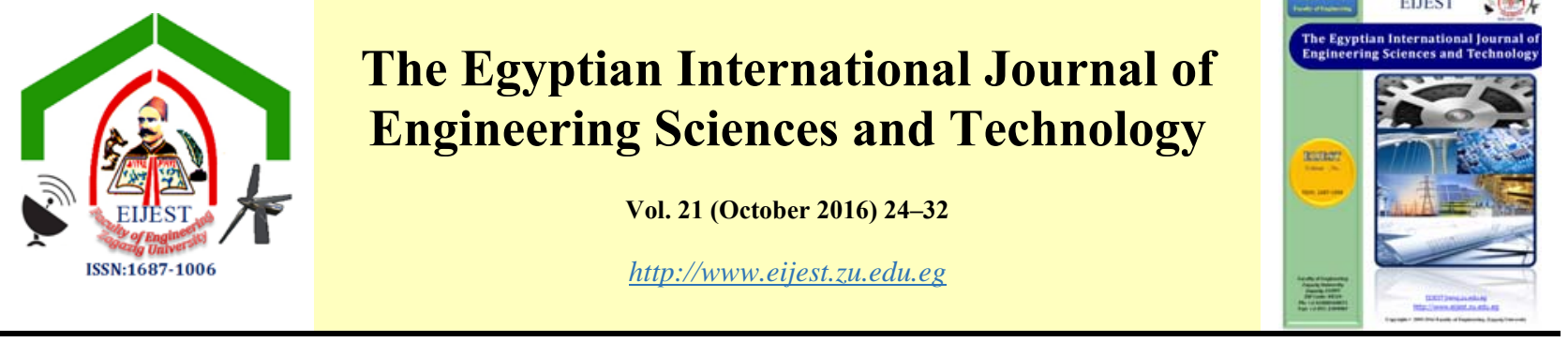

\title{
Experimental Study for the Optimization of Foundation Shapes on Soft Soil
}

\author{
N. R. El-Sakhawy, T. N. Salem, A. A. Al-Tuhamy and A. A. El_Latief* \\ Structural Eng. Dept., Faculty of Eng., Zagazig University, Egypt.
}

\begin{tabular}{|c|c|}
\hline A R T I CLE I N F O & A B S T RACT \\
\hline $\begin{array}{l}\text { Article history: } \\
\text { Received: } 27 \text { April } 2016 \\
\text { Received in revised form: } 8 \\
\text { June } 2016 \\
\text { Accepted: } 9 \text { June } 2016 \\
\text { Available online: } 22 \text { July } \\
2016\end{array}$ & $\begin{array}{l}\text { Geotechnical engineers are faced with challenges in selecting safe and economic } \\
\text { solutions for the foundations of light structures resting on deep layers of soft clay. } \\
\text { Changing the bottom of foundation shape into shell-shaped footings is a solution to } \\
\text { avoid using deep foundations or other costly soil improvement schemes. This paper } \\
\text { introduces different foundation bottom shapes that resemble the footing stress }\end{array}$ \\
\hline $\begin{array}{l}\text { Keywords: } \\
\text { Soft Clay } \\
\text { Experimental Work } \\
\text { Small Scale Model } \\
\text { Elliptical Shape } \\
\text { Shell Foundaion }\end{array}$ & $\begin{array}{l}\text { distribution over the underlying soft solls in an effort to minimize its effect. } \\
\text { Elliptical, trapezoidal and inverted folded footings have been used as an alternative } \\
\text { to the conventional flat shallow footings. The purpose of the current study is to } \\
\text { present the optimal shape of the foundations, which achieves soil stress reduction, } \\
\text { settlements, and consequently lower footing thickness and reinforcements. }\end{array}$ \\
\hline
\end{tabular}

Settlement

\section{INTRODUCTION}

In the beginning of the last century, major civil engineering projects had to be constructed in areas having thick layers of very soft to soft clay formations. These formations are known for their low shear strength, high compressibility and voids ratio, which lead to undesirable structure deformations if subjected to moderate to high loads.

This is why soft clays are considered problematic for foundation purposes. Many projects have to be constructed on soft clays. however, because of the inherent properties of soft clays, engineering problems are expected during and after construction [1].

Several methods have been utilized to overcome and enhance such clay formations in Egypt and worldwide. An adaptation of an appropriate method of enhancement will provide a suitable factor of safety and minimize any unforeseen failures and costs for remedial works. Shell footings have been found to be economical foundations, because their curved topology, have larger stiffness and strength than the corresponding plane surface structural elements. This form enables shells to put a minimum of material to maximize structural advantages $[2,3,4]$.

Experimental investigations have reported the behavior of the shell structure and their findings of these investigations have a direct effect on the construction cost of shell footings as compared to conventional flat ones [5,6].

Experimental investigation is performed on shell footings to determine the contact pressure distribution under the footings as a function of the ultimate load. The shell models were compared to circular and square flat models. Results indicated that

\footnotetext{
* Corresponding author. Tel.: +2-010-0134-9551.

E-mail address: tefa_10482@yahoo.com.
} 
the settlement of the shell was significantly reduced when compared with flat footing models [7].

\section{EXPERIMENTAL WORK}

This section presents a detailed description of the experimental work activities that have been performed in the geotechnical laboratory of the faculty of the engineering at Zagazig University. The experimental work of the current research is devoted to exploring the behavior of different footing shapes resting on soft clay.

\subsection{Components of the Experimental Model}

\subsubsection{Testing Tank}

Figure 1 shows a schematic view of the experimental model used in this study. The test tank has inside dimensions of $1.20 \times 1.20 \mathrm{~m}$ in plan, and $0.8 \mathrm{~m}$ in depth, the wall thickness of the tank is 3 $\mathrm{mm}$. The tank box is built rigid and stiffened from all sides to prevent any lateral side movement during testing. The inside walls of the tank are polished smooth to reduce friction with the soil as much as possible by using galvanized coat on the inside wall.

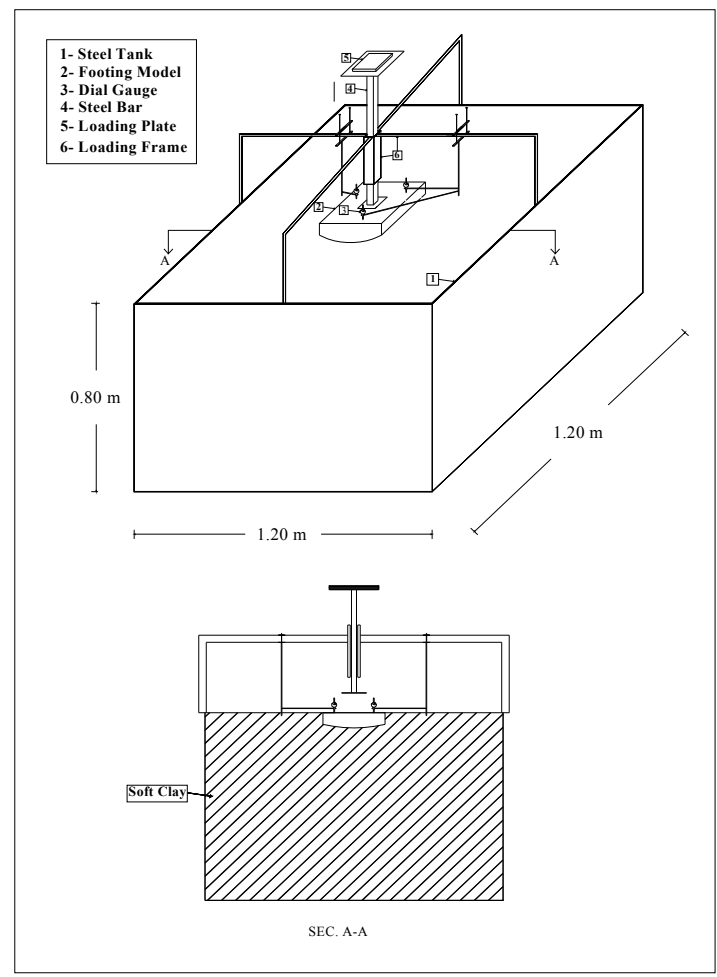

Figure(1) Schematic View of the Experimental Model.

\subsubsection{Foundation Models}

The footing models are made of hollow steel plate box-sections with constant widthand length $(\mathrm{L}=$ $\mathrm{B}=25 \mathrm{~cm}$ ) in horizontal projection, with different embedment depths ( $D$ and $d$ ). The weight of all footing constant and equal to $3 \mathrm{~kg}$. Photo(1) presents the different foundation models.

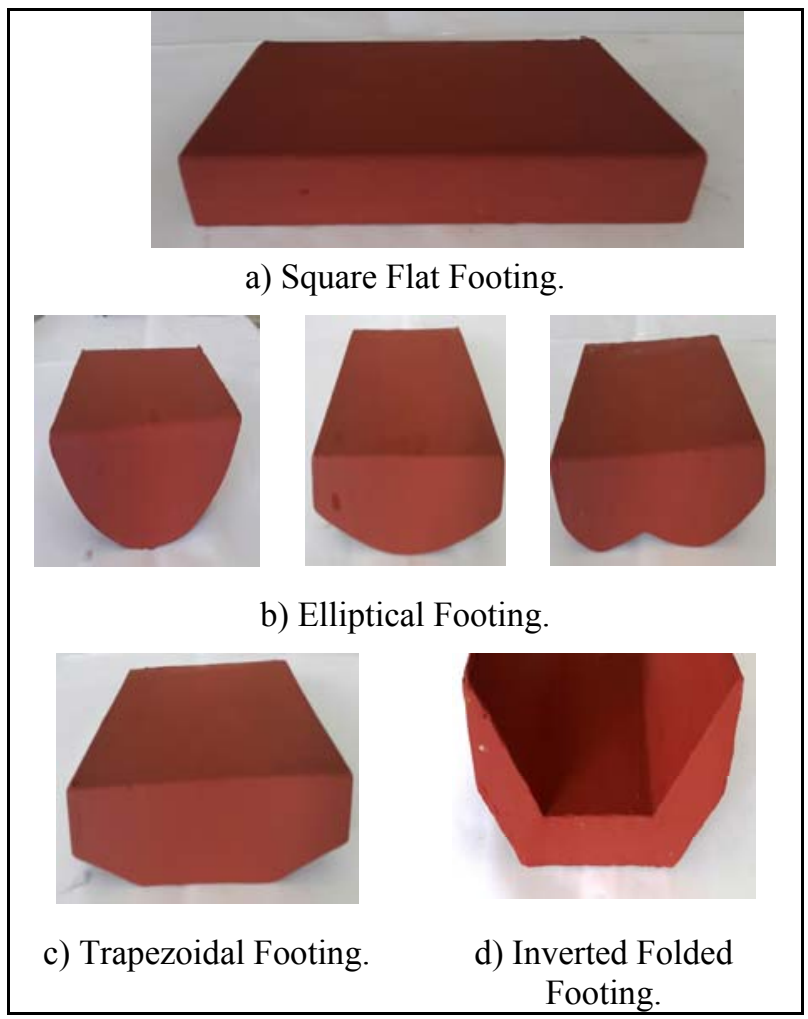

Photo (1): Different Shapes of Footing Models.

\subsubsection{Loading Frame}

The loading frame consists of four inverted (V) elements with (L) section welded in the walls of the tank and at the height $(50 \mathrm{~cm})$ from the surface of the tank. The four inverted (V) elements welded with square hollow steel box section at the centerline of the tank with dimension $40 * 40 \mathrm{~mm}$ in plane and 200 $\mathrm{mm}$ in height.

\subsubsection{Loading Device}

A steel loading bar is placed over the footing to transmit the applied loads to the footing center. The bar is attached to a welded plate with dimensions of $300 * 300 \mathrm{~mm}$ in the plane. Typical oedometer apparatus loads are used to provide the applied footing loads. The advantage of using the typical oedometer loads in comparison when compared with 
hydraulic jacks is the ability to maintain the applied stress for the required testing time without reduction in the applied stress due to the resulting settlement. Photo (2) shows the steel testing tank filled with soft clay, the footing, along with the loading system.

Three dial gauges are affixed on the top surface of the footing to measure the settlements. The dial had a maximum travel of $25 \mathrm{~mm}$ and an accuracy of $0.01 \mathrm{~mm}$.

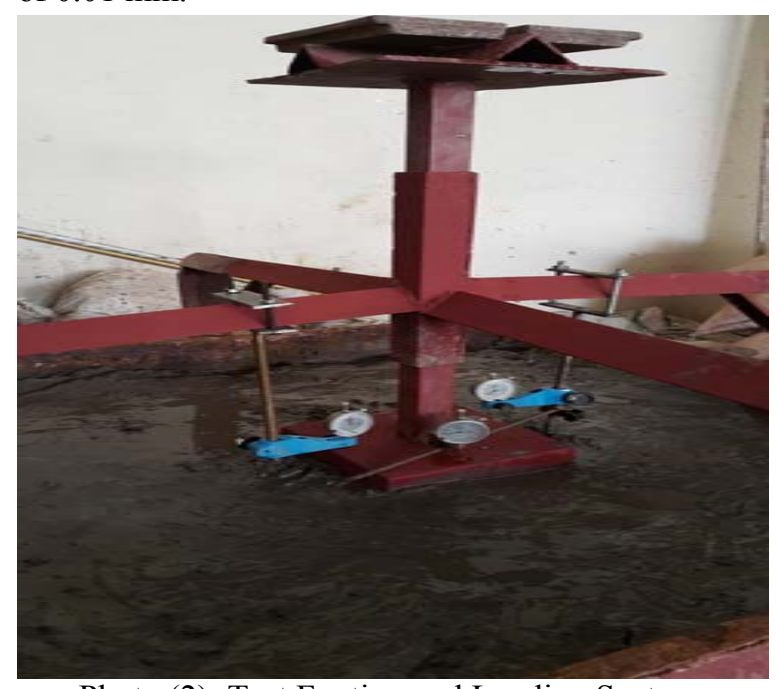

Photo (2): Test Footing and Loading System.

\subsection{Geotechnical Properties of the Tested Clay}

\section{Soil}

Natural saturated soft clay is used for the experimental investigation in this study. The soft clay is obtained from cleansing the bottom of the Mowais canal in Zagazig. Several laboratory tests are carried out to determine the physical and mechanical properties of the tested soil.

\subsubsection{Properties of Clay}

The average properties of clay used in tests are as follows:

$\begin{array}{ll}\text { Specific Gravity } & =2.64 \\ \text { Liquid Limit (L.L) } & =45.0 \% \\ \text { Plastic Limit (P.L) } & =21.0 \% \\ \text { Plasticity Index (P.I) } & =24.0 \% \\ \begin{array}{l}\text { Bulk Unit Weight } \quad\left(\gamma_{\mathrm{b}}\right) \\ \begin{array}{l}\text { Average water content during } \\ \text { the test }\left(\mathrm{W}_{\mathrm{c}}\right)\end{array}\end{array} & =41.0 \%\end{array}$

\subsubsection{Results of Consolidation Test}

Figure (2) shows the variation of the void ratio with the applied stress. Three specimens with different water content were tested under this category. The maximum applied stress was $800 \mathrm{KPa}$ for all tests.

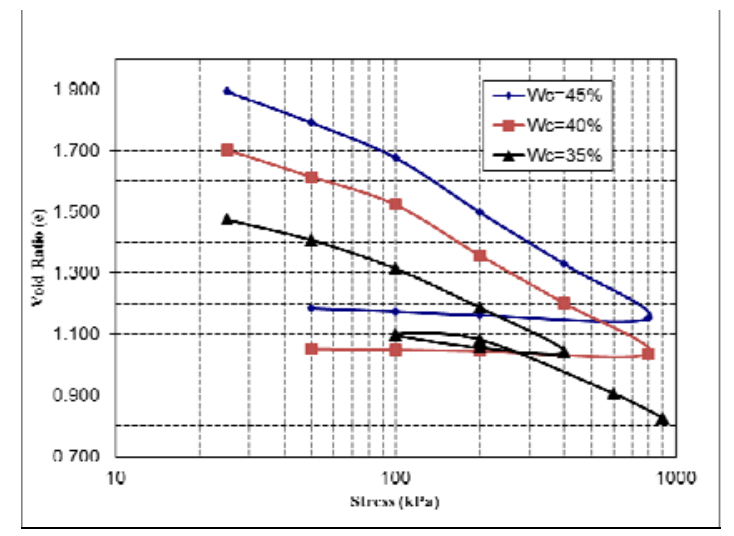

Figure (2): Consolidation Test

\section{EXPERIMENTAL TESTING PROGRAM}

In this study, eleven footing models have been tested in the laboratory to investigate the factors affecting the response of square flat bottom and shell footings resting on soft clay. These models are chosen to represent the four groups of footing shapes, as shown in Figure (3) and Table (1). The model footings used in experimental work are subdivided into four groups as follows:

Group 1: Flat bottom footing model, representing square footing measuring $250 \mathrm{~mm} *$ $250 \mathrm{~mm} * 50 \mathrm{~mm}$

Group 2: Elliptical bottom footing model representing four different elliptical footings with constant length and width $(\mathrm{L}=\mathrm{B}=250 \mathrm{~mm})$ with different depths.

Group 3: Trapezoidal footing model representing three different shapes with constant length and width $(\mathrm{L}=\mathrm{B}=250 \mathrm{~mm})$ having different angles of the lower part of the footings.

Group 4: Inverted folded footing model representing three different shapes with constant length and width $(\mathrm{L}=\mathrm{B}=250 \mathrm{~mm})$ and different angles of the lower part of the footings. 


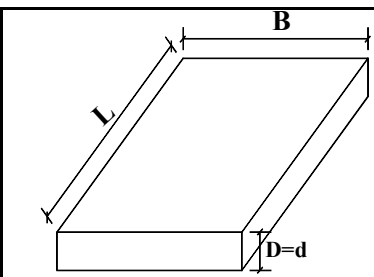

Group 1 Square Flat Footing

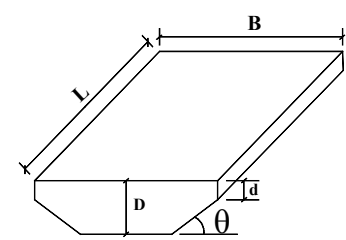

Group 3 Trapezoidal Footing

Figure (3): Four Groups of Footing Shapes.

\begin{tabular}{|c|c|c|c|c|c|c|}
\hline Group & Foundation Model & Code & Foundation Shape & $\underset{(\mathrm{mm})}{\mathrm{D}}$ & $\underset{(\mathrm{mm})}{\mathbf{d}}$ & $\theta$ \\
\hline & & & B & & & \\
\hline 1 & Square Flat Model & (SFM) & $D=d$ & 50 & 50 & - \\
\hline \multirow{4}{*}{2} & Elliptical Model 1 & (EM 1) & \multirow{2}{*}{ B } & 60 & 30 & - \\
\hline & Elliptical Model 2 & (EM 2) & & 65 & 15 & - \\
\hline & Elliptical Model 3 & (EM 3) & & 75 & 0 & - \\
\hline & Two Elliptical Model & (TEM) & 4 & 60 & 30 & - \\
\hline \multirow{3}{*}{3} & Trapezoidal Model 21 & (TM 21) & \multirow{3}{*}{ B } & 54 & 30 & 21 \\
\hline & Trapezoidal Model 31 & (TM 31) & & 57 & 20 & 31 \\
\hline & Trapezoidal Model 40 & (TM 40) & & 62 & 10 & 40 \\
\hline \multirow{3}{*}{4} & Inverted Folded Model 40 & (IFM 40) & \multirow{3}{*}{$\mathrm{B}$} & 92 & 40 & 40 \\
\hline & Inverted Folded Model 35 & (IFM 35) & & 92 & 40 & 35 \\
\hline & Inverted Folded Model 31 & (IFM 31) & & 92 & 40 & 31 \\
\hline
\end{tabular}

Table (1): Footings Model Dimensions Used in the Experimental Work.

\section{SETUP AND PROCEDURE OF TESTING}

The following procedure and sequence of work is applied, as relevant to the configuration of a tested model.

- The clay used in this study is saturated soft natural clay obtained from cleansing the bottom of Moways canal near Al-Azhar University Branch in the Zagazig city.

- The clay is packed in plastic barrels to keep their water content unchanged. These barrels are then transported to the soil laboratory for testing.

- $\quad$ The clay is placed in the tank in four layers to reach the required height $(80 \mathrm{~cm})$. During placement of each layer, provisions are taken to expel any air voids between the clay and the sides of the tank. For each layer checks are made for the natural water content $\left(\mathrm{W}_{\mathrm{c}}\right)$ and bulk unit weight $\left(\gamma_{\mathrm{b}}\right)$ to ensure that changes in $\mathrm{W}_{\mathrm{c}}$ and $\gamma_{\mathrm{b}}$ are within $\pm 5 \%$ range.

- $\quad$ After reaching the designated clay level (80 $\mathrm{cm}$ ), the surface of the clay is carefully leveled to form final soil surface.

- The footing is carefully placed on the centerline of the tank, three dial gauge are affixed on the surface of the footing before applying the vertical load.

- Loading frame and the loading device are adjusted to ensure axial loading conditions on the footing.

- The loading sequence proceeded with small increments up to required stress level. Each load step on the footing is maintained for 24 hours in all the performed tests.

\section{EXPERIMENTAL TESTS RESULTS 5.1 Results of Group 1}

This group includes only square flat bottom footing; the footing is placed on soft clay and is loaded with steel plates of $2 \mathrm{kN}$ in total weight to get the needed pressure. The test duration was 8 days. The stress on the footing is applied in small increments. The total net pressure is applied in eight equal steps of $4 \mathrm{kPa}$ each to reach a total of $32 \mathrm{kPa}$, with settlements measured just after loading (immediate settlement) and at the end of each loading step after $24 \mathrm{hrs}$. It should be noted that the total net 
pressure included the own weight of the footing model, the steel loading bar, and the top steel plate.

The final measured settlement in the experimental study for the case of square flat footing was equal to $82.41 \mathrm{~mm}$. Figure (4) shows the variation of the measured settlement at the end of each loading step/width (S/B) with the applied pressure. Test results showed a steep increase in settlements with increasing the applied pressure. However, increasing the applied pressure over $28 \mathrm{kPa}$ resulted in increased rate of settlements than that recorded at lower stress levels. Such settlement increase is considered an initiation of settlement failure. This case is considered a reference for all the forthcoming test cases.

Applied Pressure (KPa)

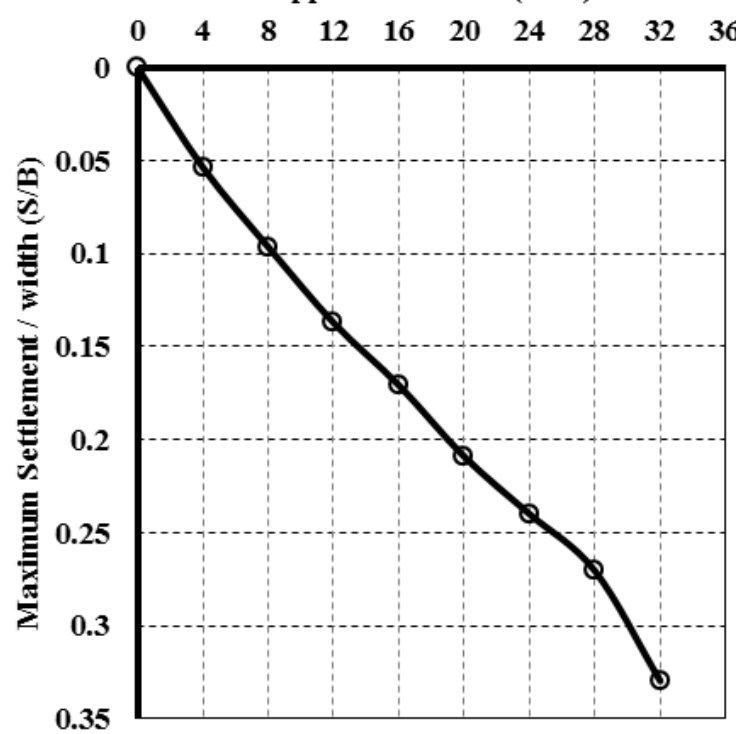

Figure (4): Applied Pressure - Settlement Curve of Square Flat Footing.

\subsection{Results of Group 2}

Test Group 2 included four models, denoted as elliptical footing1, elliptical footing2, elliptical footing 3 and a footing with two elliptical bottom surface. As described in Table (1), elliptical footings has the same length $(\mathrm{L})=250 \mathrm{~mm}$, width $(\mathrm{B})=250$ $\mathrm{mm}$, different total depths (D) of $60,65,75$, and 60 $\mathrm{mm}$ and different side depths (d) of 30, 15, 0, and 30 $\mathrm{mm}$ respectively. Data are further analyzed and compared with results obtained from the reference test for square flat model in group 1. Comparison of settlements measured for footings with flat and elliptical bottom shapes is made at different stress levels. From the comparisons, it is clear that the elliptical shape has a noticeable effect in reducing the measured settlements. Figure (5) presents the applied pressure - settlement ratio $(\mathrm{S} / \mathrm{B})$ curves for the tests in groups 1 and 2. The measured total settlements for the elliptical footing EM3 and TEM are 70.93 and $66.45 \mathrm{~mm}$ respectively. Reduction in total settlements ranging between $13.90 \%$ and $19.30 \%$ took place due to changing the bottom of footing shape from flat into elliptical with different configurations.

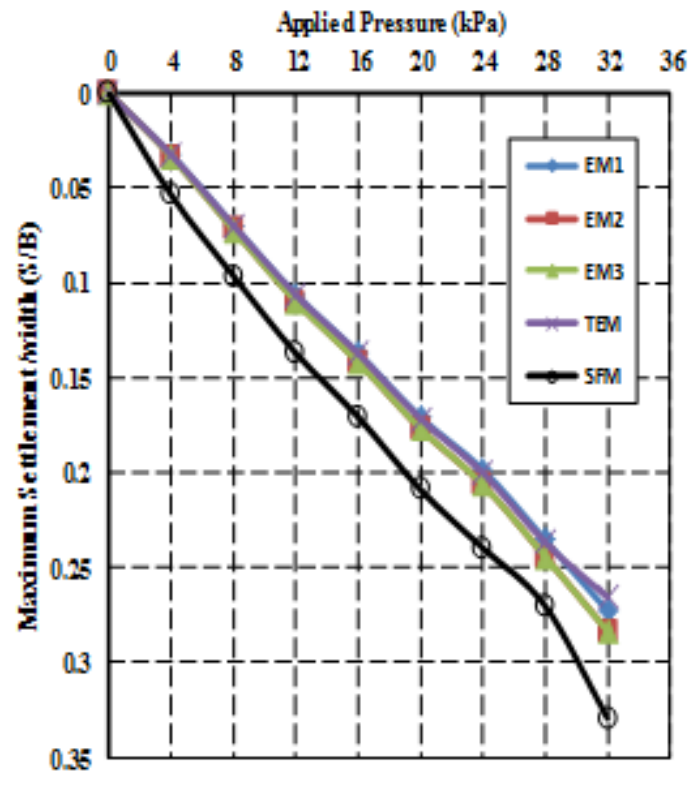

Figure (5): Applied Pressure- Settlement Curve of Group1 and Group2.

\subsection{Results of Group 3}

Group 3 included three models, denoted as trapezoidal 21, trapezoidal 31 and trapezoidal 40. As described in Table (1), trapezoidal models have the same length $(\mathrm{L})=250 \mathrm{~mm}$, width $(\mathrm{B})=250 \mathrm{~mm}$, different total depths (D) of 54,57, $62 \mathrm{~mm}$, and different edge depth (d) of 30, 20, 10 and different angles $(\theta)$ of $21,31,40^{\circ}$ respectively.

Test results of group 3 along with the reference case (group 1) are shown in Figure (6). The load settlement curve trend for the flat and trapezoidal bottom footing cases is essentially the same, but with smaller measured settlements in case of trapezoidal bottom footing. The recorded maximum settlements for cases of TM21, TM31, TM40 ranged between 67.92 and $71.90 \mathrm{~m}$, giving reductions in the total settlements ranging between 12.80 and $17.60 \%$. Figure (5) also shows a relatively higher settlement rate for stresses over $28.0 \mathrm{kPa}$ in the trapezoidal footing cases as previously noted in the reference flat case. 


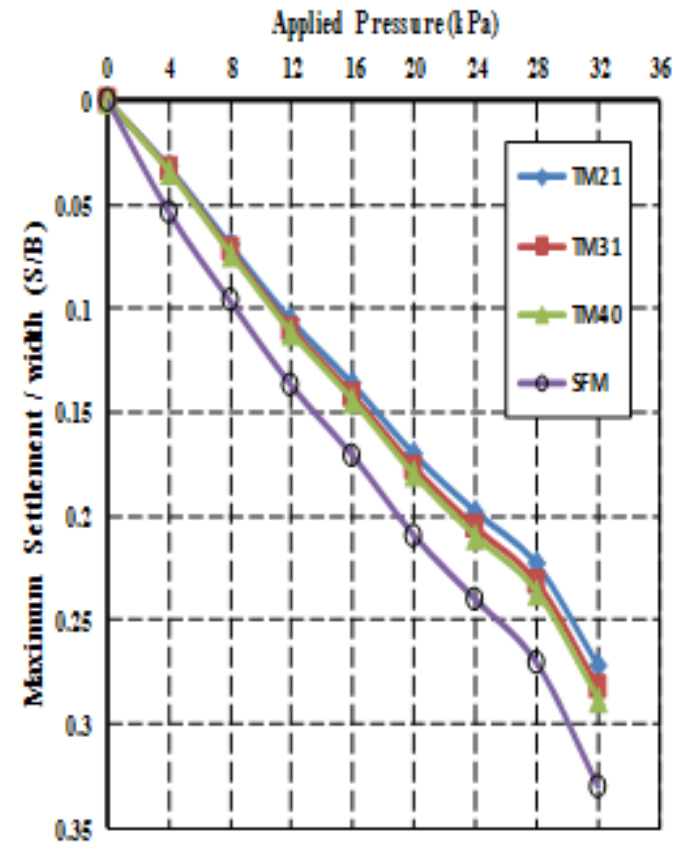

Figure (6): Applied Pressure - Settlement Curve of Groups 1 and 3.

\subsection{Results of Group 4}

Group 4 included three models, denoted as inverted folded 40 , inverted folded 35 and inverted folded31 or namely; IFM40, IFM35, and IFM31, as described in Table (1). The inverted folded footing are having the same length $(\mathrm{L})=250 \mathrm{~mm}$, width $(\mathrm{B})=$ $250 \mathrm{~mm}$, total depth $(\mathrm{D})=92 \mathrm{~mm}$, edge depth $(\mathrm{d})=$ $40 \mathrm{~mm}$, along with different angles $(\theta)$ of $40,35,31^{\circ}$ respectively. The load-settlement curve for this group is shown in Figure (7). The figure shows that increasing the applied pressure resulted in an approximate linear increase in the measured settlements. The measured total settlements for the three studied cases are ranging between 72.11 and $75.26 \mathrm{~mm}$, as compared with the reference flat bottom case of $82.41 \mathrm{~mm}$. In this case, reductions in the total settlements ranged between $8.70 \%$ and $12.50 \%$, giving the lowest reduction in the total settlements of all the studied groups.

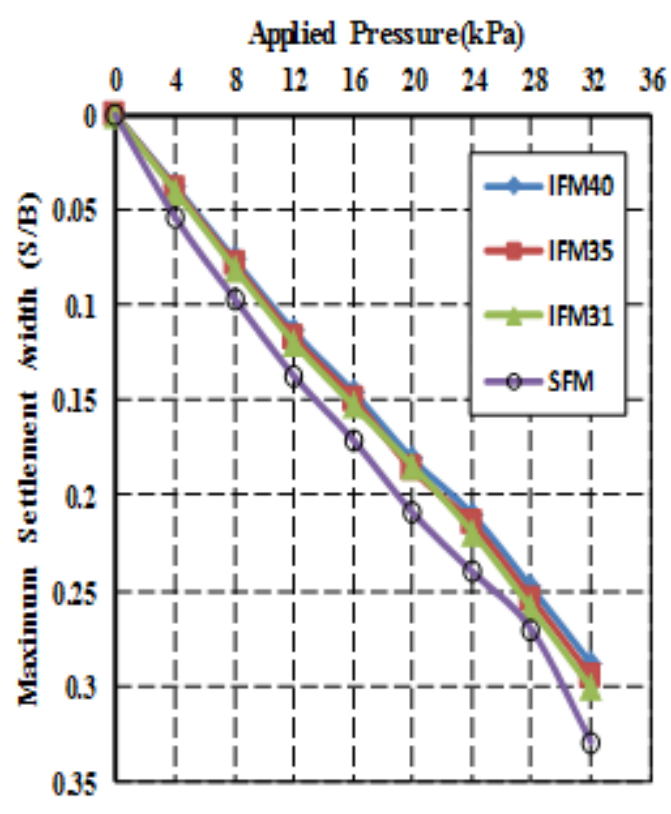

Figu

re (7): Applied Pressure - Settlement Curve of Group1 and Group4.

\subsection{Comparison Between All the Studied Footing Shape Groups}

A comparison of all the tested footing group test results is presented in Figure (8). The groups included square flat model (reference case) and the best shape of elliptical, trapezoidal and inverted folded models. Test results showed that the two elliptical model (TEM) gave the minimum settlements and consequently the best behavior of all the tested models with reductions in the total settlements of $19.40 \%$. However, the case of inverted folded model 31 (IFM31) gave the lowest total settlement reduction of all cases with $8.70 \%$ reduction. It should be noted that in all cases, the elliptical bottom footing shape gave the highest settlement reductions, while the inverted folded bottom footing shape gave the lowest reductions in settlements. In other words, curved bottom footing shapes are superior over edged bottom footing shapes, especially the inverted folded ones. 


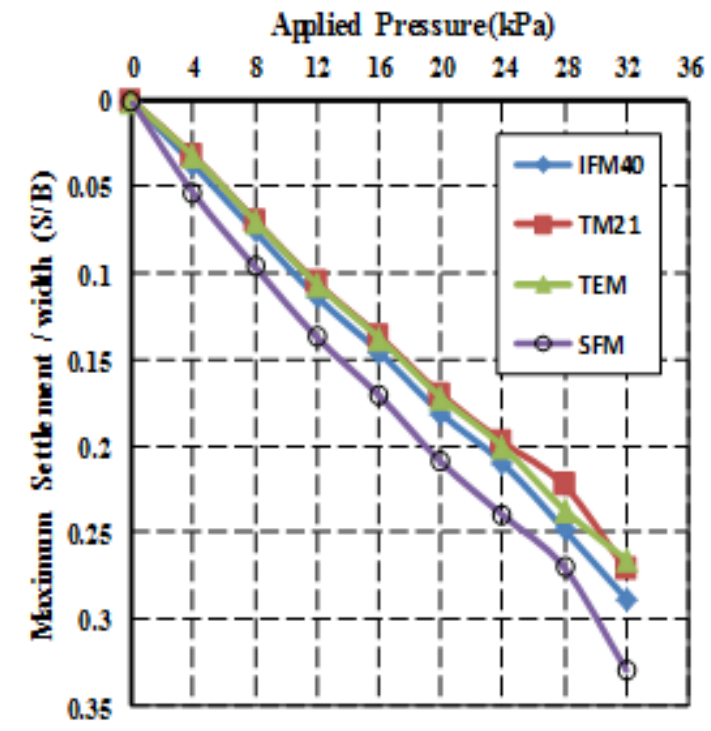

Figure (8): Applied Pressure - Settlement Curve of Group1 and Best Shape in Group 2, Group 3 and Group4.

\subsection{Effect of Increasing Applied Pressure on Soil Settlement}

Summary of the model footing test results is presented in Table (2). Test results showed all the measured settlement values under all the applied pressure. Out of all the tested models, the elliptical bottom footing shapes gave the minimum settlements, especially the EM1 and TEM modes. Tracking the measured settlements in all the stress levels for these two cases showed that the EM1 model gave the minimum settlements under all the applied stress stages except for the last loading step.

Table (2): Test Results (Total Settlement of different Footing Model) Under Different Applied Pressures.

\begin{tabular}{|c|c|c|c|c|c|c|c|c|c|c|c|}
\hline \multirow{2}{*}{ 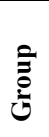 } & \multirow{2}{*}{ Foundation Model } & & \multicolumn{8}{|c|}{ Applied Pressure (kPa) } & \multirow{2}{*}{$\begin{array}{c}\text { P.R } \\
\%\end{array}$} \\
\hline & & & 4 & 8 & 12 & 16 & 20 & 24 & 28 & 32 & \\
\hline 1 & Square Flat Model & \multirow{11}{*}{ 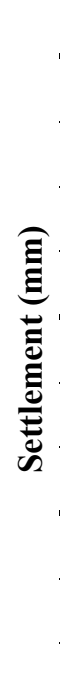 } & 13.41 & 24.1 & 34.28 & 42.68 & 52.27 & 59.98 & 67.61 & 82.41 & ---- \\
\hline \multirow{4}{*}{2} & Elliptical Model 1 (EM 1) & & 8.06 & 17.41 & 26.53 & 34.23 & 42.74 & 49.64 & 56.07 & 68.23 & 17.2 \\
\hline & Elliptical Model 2 (EM 2) & & 8.28 & 17.97 & 27.43 & 35.42 & 44.26 & 51.60 & 58.18 & 70.87 & 14.0 \\
\hline & Elliptical Model 3 (EM 3) & & 8.34 & 18.01 & 27.46 & 35.45 & 44.24 & 51.61 & 58.19 & 70.93 & 13.9 \\
\hline & Two Elliptical Model (TEM) & & 8.09 & 17.45 & 26.59 & 34.34 & 42.93 & 50.05 & 56.42 & 66.45 & 19.4 \\
\hline \multirow{3}{*}{3} & Trapezoidal Model 21 (TM 21) & & 8.02 & 17.37 & 26.45 & 34.08 & 42.51 & 49.42 & 55.73 & 67.92 & 17.6 \\
\hline & Trapezoidal Model 31 (TM 31) & & 8.3 & 17.99 & 27.42 & 35.34 & 44.1 & 51.32 & 57.87 & 70.53 & 14.4 \\
\hline & Trapezoidal Model 40 (TM 40) & & 8.44 & 18.31 & 27.9 & 35.97 & 44.93 & 52.32 & 59.00 & 71.90 & 12.8 \\
\hline \multirow{3}{*}{4} & Inverted Folded Model 40 (IFM 40) & & 9.31 & 19.00 & 28.44 & 36.38 & 45.26 & 52.46 & 59.15 & 72.11 & 12.5 \\
\hline & Inverted Folded Model 35 (IFM 35) & & 9.62 & 19.55 & 29.15 & 37.23 & 46.63 & 53.66 & 60.50 & 73.72 & 10.6 \\
\hline & Inverted Folded Model 31 (IFM 31) & & 9.94 & 20.10 & 29.91 & 38.11 & 46.12 & 54.77 & 61.76 & 75.26 & 8.7 \\
\hline
\end{tabular}

Where:

P.R: Percentage Reduction

\subsection{Time-Settlement Behavior of Different Footing Model Shapes}

Figure (9) shows the measured settlements for different model footing shapes with time at of stress
$32 \mathrm{kPa}$ applied on footing surface. From the figure, it can be seen that the settlement, increasing with increasing time until it reaches a constant value at time $1080 \mathrm{~min}$. (18 hr.), this value remains constant 
till the end of the test period after 24 hours. A single case was left for 72 hours and the measured settlements was contant after $18 \mathrm{hr}$. also.

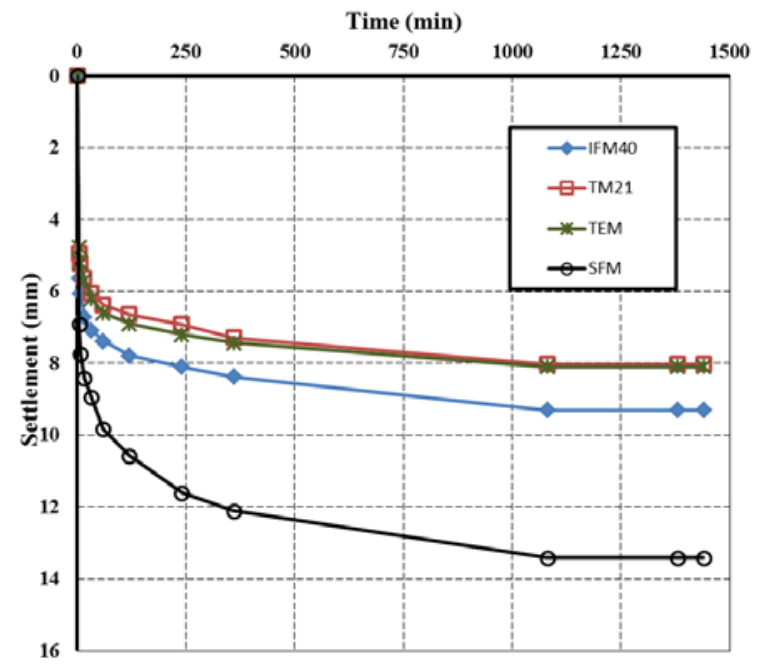

Figure (9): Time-Settlement Curves of Different Footing Shapes.

\subsection{Bearing Capacity of Different Footing Shapes}

According to the Egyptian code of practice [8], Terzaghi's classical bearing capacity equation is used to calculate the bearing capacity under the square flat footing considering a footing width (B) equal to $250 \mathrm{~mm}$ which is kept constant for all models. Considering the soft clay undrained cohesion equal to $15 \mathrm{kPa}$, the bearing capacity constant for different footing bottom shape is equal to $45 \mathrm{kPa}$. In this case, the settlement failure is the main concern which will take place well before the shear failure would take place.

\section{Practical Application}

Reduction of the total settlements will allow for increasing the applied pressure to reach the same total settlements allowable for the flat bottom footing case. Allowing for higher stresses at the same acceptable settlement level will allow for higher structures to be constructed in the saturated soft clays covering large zones in northern Egypt. However, in practice flat bottom footings are typical and easier to construct. The suitable footing material that can be formed in the tested shapes are prefabricated light weight concrete unit. The footing unit should be provided with central steel dowels arranged to be connected later with the column reinforcement.

The proposed prefabricated light weight concrete units can be arranged in a grid to form a foundation for ordinary light weight structures. Line arrangement will form a suitable base layer for highways. Other advantages of these units are eliminating the need for excavation and dewatering of the construction site. In addition, time and cost savings will be considerable.

The behavior of a group of prefabricated footings will be better than the single footing behavior. As lower stresses took place under single elliptical shape bottom footings, extra lower stresses will eventually take place under a group of connected elliptical footing units. Further details will be presented in a forthcoming paper presenting and extended numerical analysis of the current research.

However, full scale field testing should be performed on zones of soft saturated Egyptian soils to reach concrete conclusions regarding the proposed technique.

\section{CONCLUSIONS}

This paper presents the experimental work of the flat and different footing bottom shapes resting on saturated soft clay. The aim of the study is to highlight the effectiveness of changing the shape of the bottom of footing to choose the optimal shape. The experimental work is performed using eleven different footing model shape on saturated soft clay. The footing shape divided into four groups of square flat, elliptical, trapezoidal, and inverted folded models. Based on the results of this investigation, the following main conclusions can be drawn:

1- Elliptical bottom footing shape gave the highest settlement reductions assuring that the curved bottom footing shapes are superior over any other footing bottom shape. About $20 \%$ reduction in the total settlements is measured in this case.

2- This reduction in the total settlement will allow for increasing the applied pressure and consequently allowing for construction larger structures, or even constructing light weight structures in previously prohibited zones.

3- Trapezoidal and inverted folded bottom footing models gave lower settlement reductions, with trapezoidal ones giving better performance than the inverted folded ones. $17.60 \%$ reduction in settlements could be achieved in the trapezoidal footings, while these reductions could reach up to $12.50 \%$ reduction in the inverted folded ones.

4- Special prefabricated light weight concrete footing units can be used for practical application of the proposed footing shapes to be constructed over saturated soft clays. 


\section{REFERENCES}

[1] Nagaraj, T.S., and Miura, N. (2001). "Soft Clay Behavior, Analysis and Assessment", A.A. Balkema, Rotterdam, Netherlands.

[2] Abdel-Rahman, M.M. (1996). "Geotechnical Behavior of Shell Foundations," Ph.D. Thesis, Civil Engineering, Concordia University, Montreal, Quebec, Canada, pp. 126-137.

[3] Esmaili, D., and Hataf, N. (2008). "Experimental and Numerical Investigation of Ultimate Load Capacity of Shell Foundations on Reinforcedand Unreinforced Sand" Iranian Journal of Science \& Technology, Transaction B, Engineering, Vol. 32, No. B5, pp 491-500.

[4] Alhassan, M., Boiko, I.L. (2013). "Experimental Study of the Effect of Foundation Shape on Settlement and Bearing Capacity of Soils," International Journal of Engineering and Technology Vol. 3, No. 2. pp.
[5] Kurian, N.P., and Jayakrishna Devaki, V.M. (2005). "Analytical Studies on the Geotechnical Performance of Shell Foundations," Canadian Geotechnical Journal, Vol. 42, No. 2, pp. 562-573.

[6] Hanna, A.M. and Abdel-Rahman, M. (1998). "Experimental Investigation on Shell Foundations on Dry Sand", Canadian Geotechnical Journal. 35(6): 828-846.

[7] Nicholls, R.L. and Izadi, M.V. (1968). "Design and Testing of Cone and Hypar Footings", Journal of Soil Mechanics and Foundation Engineering, Vol.94, pp.47-72.

[8] Egyptian Code of Practice for Soil Mechanics and Design and Construction of Foundations, (2002), Part 3, Shallow Foundations. 